\title{
The second locus for autosomal recessive primary microcephaly (MCPH2) maps to chromosome 19q13.1-13.2
}

\author{
Emma Roberts ${ }^{1}$, Andrew P Jackson ${ }^{1}$, Abigail C Carradice $^{1}$, V Jayne Deeble ${ }^{1}$, \\ Jovaria Mannan ${ }^{2}$, Yasmin Rashid ${ }^{3}$, Hussain Jafri ${ }^{4}$, Duncan P McHale ${ }^{1}$, Alex F \\ Markham ${ }^{1}$, Nicholas J Lench ${ }^{1}$ and C Geoffrey Woods ${ }^{5}$ \\ ${ }^{1}$ Molecular Medicine Unit, University of Leeds, St James's University Hospital, Leeds, UK \\ ${ }^{2}$ Fatima Jinnah Medical College, Lahore, Pakistan \\ ${ }^{3}$ Rawalpindi Medical College, Rawalpindi, Pakistan \\ ${ }^{4}$ Genetech Laboratories, Lahore, Pakistan \\ ${ }^{5}$ Yorkshire Regional Clinical Genetics Service, St James's University Hospital, Leeds, UK
}

\begin{abstract}
Primary microcephaly is a clinical diagnosis made when an individual has a head circumference of greater than 3 standard deviations below the age and sex matched population mean, mental retardation but without other associated malformations and no apparent aetiology. The majority of cases of primary microcephaly exhibit an autosomal recessive mode of inheritance. We now demonstrate the genetic heterogeneity of this condition with the identification of a second primary microcephaly locus (MCPH2) on chromosome 19q13.1-13.2 in two multi-affected consanguineous families. The minimum critical region containing the $M C P H 2$ locus is defined by the polymorphic markers D19S416 and D19S420 spanning a region of approximately $7.6 \mathrm{cM}$.
\end{abstract}

Keywords: microcephaly; 19q13; homozygosity mapping; $M C P H 2$

\section{Introduction}

Microcephaly is defined as a disorder with a head circumference of greater than 3 standard deviations below the population mean for age and sex in the absence of craniosynostosis. ${ }^{1}$ Primary microcephaly is a non-syndromic, predominantly autosomal recessive form of microcephaly defined by an absence of identifiable environmental causes and a lack of associated

Correspondence: Emma Roberts, Molecular Medicine Unit, University of Leeds, Clinical Sciences Building, St James's University Hospital, Beckett Street, Leeds, LS9 7TF, UK. Tel: + 441132065681 ; Fax: + 441132444475 ; E-mail: mmeer@leeds.ac.uk

Received 15 April 1999; revised 29 June 1999; accepted 7 July 1999 malformations. ${ }^{2,3}$ Apart from mental retardation there are no significant neurological deficits, with the small head circumference explained by an apparently structurally normal but small brain (micrencephaly). ${ }^{4}$ Given a diagnosis of primary microcephaly, the recurrence risk for a further affected child is approximately 1 in 6 , although if the parents are related, or symmetrical micrencephaly is confirmed by neuroimaging, then a recurrence risk approaching 1 in 4 is suggested. ${ }^{4,5}$ These empirical data, along with segregation studies, ${ }^{6,7}$ suggest that most cases of primary microcephaly are likely to be autosomal recessive, with an incidence of approximately 1 in 30000 to 1 in $2500000^{8,9}$

Primary microcephaly has been previously proposed to be a genetically heterogeneous disorder, ${ }^{10}$ therefore multiple separate autosomal recessive loci are likely to 
exist. Additionally, genetic heterogeneity of the condition was recently suggested by the identification of a first locus (MCPH1) on chromosome 8p22.3-8pter in a large consanguineous family, with the finding that seven of eight other consanguineous families are unlikely to be linked to this locus. ${ }^{11}$

The study of microcephaly may offer insights into human brain evolution and development and further our understanding as to how a substantial decrease in brain volume seen in affected individuals results in only a comparatively small reduction in intelligence. However, from a clinical stand point, the disorder remains difficult to diagnose with certainty and whilst the recurrence risk is substantial, prenatal diagnosis is not feasible before 26 weeks of pregnancy. ${ }^{12}$

\section{Materials and Methods}

\section{Clinical Studies}

The diagnostic features of our patients with autosomal recessive primary microcephaly were a head circumference measurement of at least 3 standard deviations (SD) below the mean with no craniosynostosis, mild to moderate mental retardation (none could be educated in a normal school, but all are able to clean, dress, feed themselves and partake in limited conversation; all motor milestones were normal). They had no significant dysmorphic features and no neurological or ophthalmic findings. Microcephaly was noted by the parents at birth. None of the parents is microcephalic or mentally retarded. From a cohort of consanguineous families ascertained in Yorkshire, UK and the Punjab, Pakistan, two large families (PM1 and PM2) with six and nine affected individuals respectively were chosen for further genetic analysis (Figure 1). Both kindreds were of Northern Pakistani origin. For all affected individuals a history was taken, an examination performed and syndrome diagnoses excluded. For both families studied the inheritance pattern was compatible with an autosomal recessive trait. A typical affected individual is shown (Figure 2) who is not dysmorphic and is of normal stature and in good health. He has a head circumference of $-6 \mathrm{SD}$ and static mild mental retardation with no progressive neurological defects and no fits. The head circumferences of the affected individuals in families PM1 and PM2 varied between -4 and -7 SDs below the mean for age and sex. The phenotype in the two families was clinically indistinguishable. Peripheral blood samples were taken for DNA extraction with informed consent. Chromosome analysis was performed on two affected individuals in each family and no anomalies were detected at the 550 band level. Neuroimaging data is not currently available for affected individuals from these two families.

\section{Extraction of DNA and Genotyping}

DNA was extracted from peripheral blood lymphocytes by a standard non-organic extraction procedure. The two families were analysed with markers on chromosome 8 and neither family showed linkage to the $M C P H 1$ locus at $8 \mathrm{p} 22.3-8 \mathrm{pter}$ (data not shown). The ABI Prism Linkage Mapping Set,
Version 1.0 (Applied Biosystems, Perkin Elmer, Kelvin Close, Birchwood Science Park, Warrington WA3 7PB, UK), comprising 358 microsatellite markers at an average spacing of $10 \mathrm{cM}$, was used to perform a genome-wide search in family PM1. PCR amplification of the 343 autosomal markers was carried out according to the manufacturer's specifications. Amplified markers were pooled, loaded on a $4.2 \%$ denaturing polyacrylamide gel and electrophoresed at $3000 \mathrm{~V} / 52^{\circ} \mathrm{C}$ for 2.5h on an ABI 377 Sequencer. Fragment length analysis was performed using the ABI Prism Genescan and Genotyper 1.1.1 software. Fine mapping of the region on chromosome 19 was carried out using the markers D19S416, D19S570 and D19S881 selected from the Genome Database (http:/ /gdbwww.gdb.org). For these markers, PCR reactions were carried out in $10 \mu \mathrm{l}$ reaction volumes containing $50 \mathrm{ng}$ of genomic DNA, 10 pmol of primers, $200 \mu \mathrm{m}$ each of dGTP, dATP, dTTP, dCTP, 5U of Taq DNA polymerase, and $1 \times$ reaction buffer $(10 \mathrm{~mm}$ Tris- $\mathrm{HCl} \mathrm{pH} 9.0,50 \mathrm{~mm} \mathrm{KCl}, 1 \%$ Triton X-100). Amplification was as follows: $95^{\circ} \mathrm{C}$ for $5 \mathrm{~min}$, 35 cycles of $95^{\circ} \mathrm{C}$ for $30 \mathrm{~s}, 50-55^{\circ} \mathrm{C}$ for $30 \mathrm{~s}, 72^{\circ} \mathrm{C}$ for $30 \mathrm{~s}$, with a final incubation step of $72^{\circ} \mathrm{C}$ for $10 \mathrm{~min}$.

\section{Linkage Analysis}

Allele frequencies for the study markers on chromosome 19 were determined in 34 unrelated individuals of Northern Pakistani origin. Two-point analysis was performed using the LINKAGE analysis programs, ${ }^{13}$ assuming a full penetrance, an autosomal recessive mode of inheritance and a disease gene allele frequency of 0.003 . GENEHUNTER 2.0 beta was used for multipoint analysis, ${ }^{14}$ using the same parameters and inter-marker distances derived from the Marshfield linkage map (The Genome Database. http://gdbwww.gdb.org).

\section{Results}

All six affected individuals from family PM1 were analysed with the autosomal markers from the ABI Prism Linkage Mapping Set. A homozygous region of approximately $60 \mathrm{cM}$ on chromosome 19q13.1-13.2 between markers D19S226 and D19S418 was seen in all six individuals (Figure 1A). Family PM2 (Figure 1B) was then analysed for evidence of linkage to chromosome 19. Seventeen individuals were typed and a region of homozygosity was found in all nine affected individuals consistent with that for family PM1, and further defining the minimal critical region. The Genome Database was searched for polymorphic markers within this region and both families analysed further using three additional dinucleotide repeat markers, D19S416, D19S570 and D19S881 situated between D19S226 and D19S420. The minimum critical region (the smallest homozygous region common to all affected individuals) is an interval of about $7.6 \mathrm{cM}$ between D19S416 and D19S420. Two-point analysis of the markers in this region (Table 1$)$ gave a maximum lod score $\left(Z_{\max }\right)$, at a recombination fraction $(\theta)$ of zero, of 5.28 for marker D19S420 for family PM1 and 4.57 for marker D19S570 
A

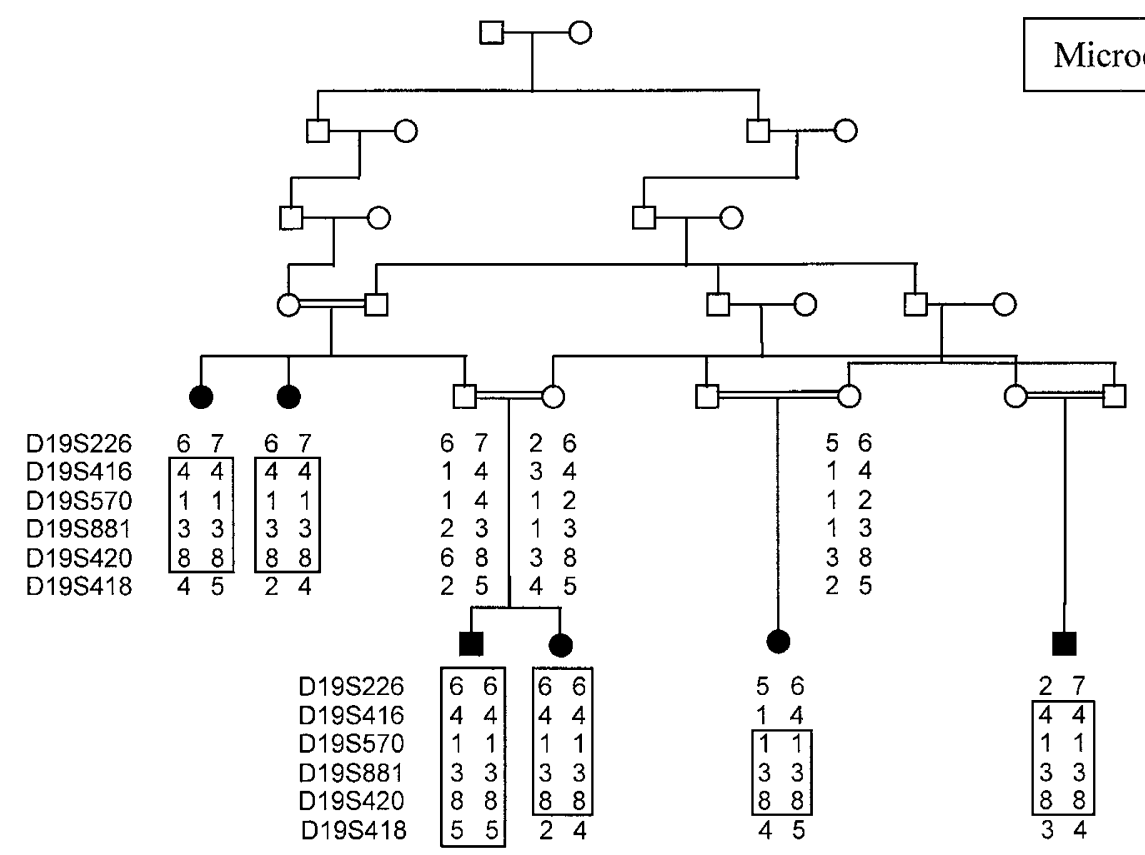

B

Microcephaly $\mathbf{\bullet}$

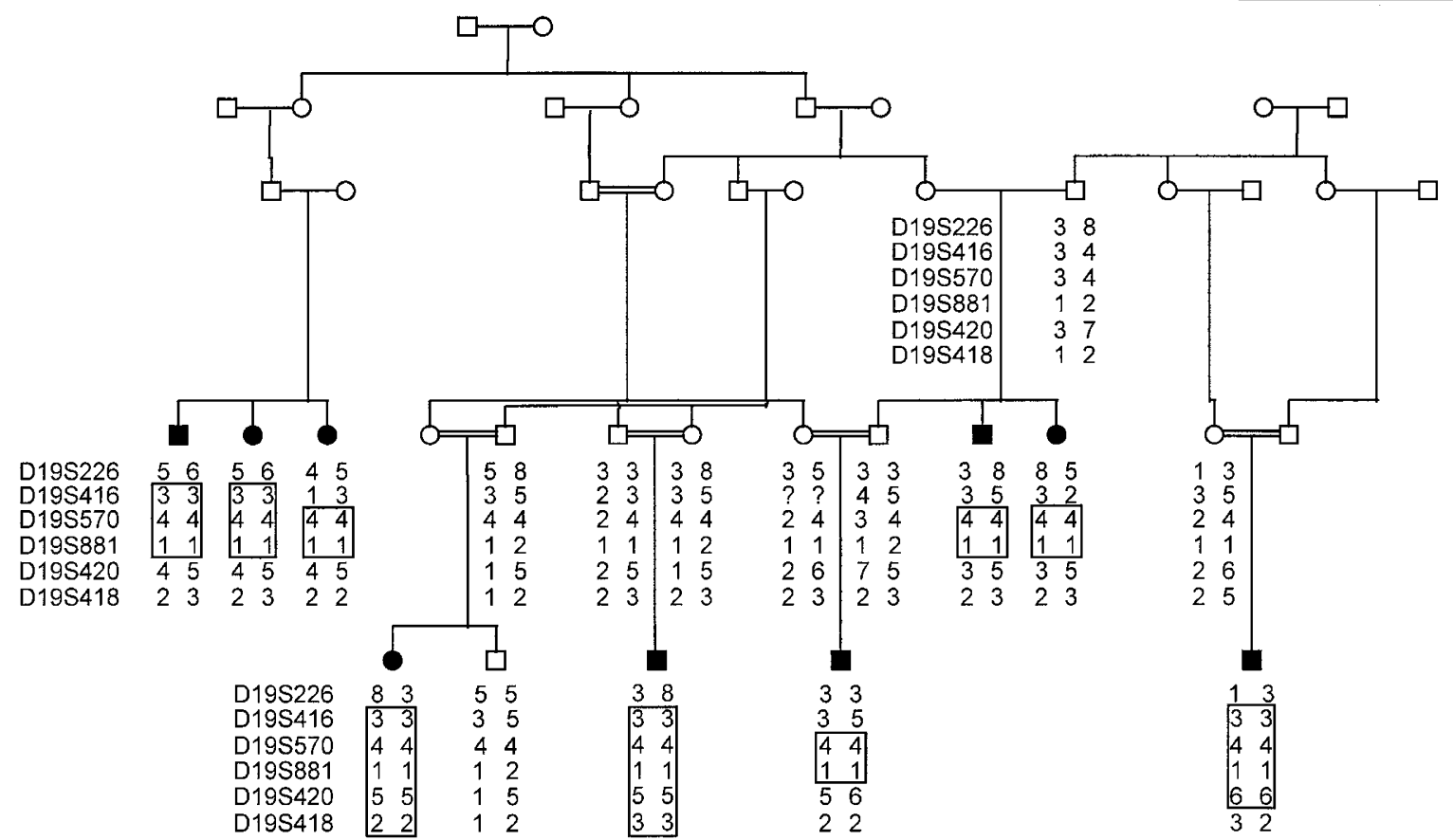

Figure 1 A Genotypes for six markers on 19q13 for family PM1 (unaffected siblings have been omitted for clarity). Marker order and relative distances from the Marshfield linkage map (http://gdbwww.gdb.org):cen-D19S226-16cM-D19S416-3.3cMD19S570-1cM-D19S881-3cM-D19S420-26cM-D19S418-tel. B Genotypes for six markers on 19q13 for family PM2 (most unaffected siblings have been omitted for clarity). Marker order and relative distances as for Figure $1 \mathrm{~A}$

for family PM2. Multipoint analysis for both the families (Figure 3 ) derived a maximum lod score of 6.49 for family PM1 at D19S881 and 4.40 at D19S570 for family PM2. 


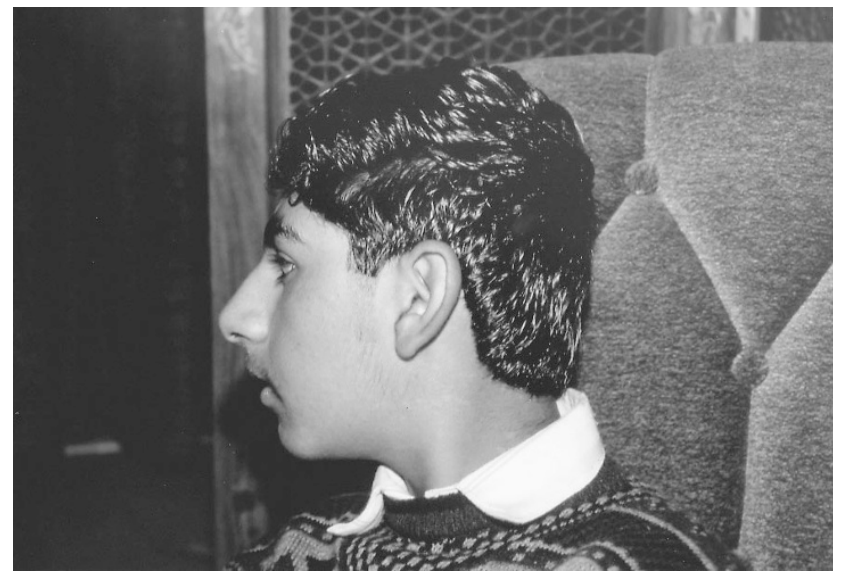

Figure 2 An individual with primary microcephaly at 14 years with a head circumference of $-6 S D$

Table 1 Two-point lod scores for families PM1 and PM2

\begin{tabular}{lrrrrrrrr}
\hline & \multicolumn{7}{c}{ Lod score at recombination fraction of } \\
\cline { 2 - 8 } Marker & 0.0 & 0.01 & 0.05 & 0.1 & 0.2 & 0.3 & 0.4 \\
\hline D19S226 & & & & & & & \\
PM1 & -7.30 & -3.60 & -1.40 & -0.51 & 0.07 & 0.15 & 0.08 \\
PM2 & $-\infty$ & -6.71 & -3.59 & -2.26 & -1.10 & -0.57 & -0.25 \\
D19S416 & & & & & & & \\
PM1 & 1.48 & 3.13 & 3.39 & 3.14 & 2.31 & 1.37 & 0.52 \\
PM2 & $-\infty$ & -1.17 & 0.45 & 0.80 & 0.65 & 0.28 & 0.04 \\
D19S570 & & & & & & & \\
PM1 & 4.12 & 4.02 & 3.62 & 3.12 & 2.12 & 1.19 & 0.44 \\
PM2 & 4.57 & 4.44 & 3.96 & 3.34 & 2.15 & 1.09 & 0.34 \\
D19S881 & & & & & & & \\
PM1 & 4.91 & 4.81 & 4.37 & 3.81 & 2.66 & 1.54 & 0.60 \\
PM2 & 4.01 & 3.91 & 3.49 & 2.97 & 1.96 & 1.05 & 0.38 \\
D19S420 & & & & & & & \\
PM1 & 5.28 & 5.17 & 4.71 & 4.13 & 2.93 & 1.72 & 0.67 \\
PM2 & -1.61 & 1.83 & 2.68 & 2.62 & 1.91 & 1.06 & 0.38 \\
D19S418 & & & & & & & \\
PM1 & $-\infty$ & -6.30 & -3.05 & -1.67 & -0.57 & -0.18 & -0.04 \\
PM2 & $-\infty$ & -4.84 & -1.99 & -0.87 & -0.11 & 0.05 & 0.04 \\
\hline
\end{tabular}

\section{Discussion}

Primary microcephaly was suspected to be genetically heterogeneous because of the number of diseases known to cause microcephaly with other clinical features and the interfamilial variability in head circumference and intelligence. In this paper we describe the identification of a second novel locus for autosomal recessive primary microcephaly, $\mathrm{MCPH} 2$, located at chromosome 19q13.1-13.2, confirming genetic heterogeneity for this condition. It has not been possible to distinguish clinically between the $M C P H 1$ and $M C P H 2$ phenotypes, implying that more than one gene can result in an apparently clinically identical primary microcephaly phenotype. However, detailed neuroimaging or neuropathological examination has not yet been performed on any affected individual's brain from our $\mathrm{MCPH} 2$ linked families. Such studies may reveal differences which would allow distinction between different genotypes and provide insights into the primary pathological defects underlying primary microcephaly.

It is assumed that the brain of an individual with primary microcephaly has a reduced number of neurones, and indeed in the mouse brain the number of neurones is proportionate to weight and size. ${ }^{15}$ However, it is possible that a glial cell deficiency or a reduction in dendritic connection complexity could also give rise to a smaller brain. Candidate genes for primary microcephaly can only be hypothesised at present, but it seems likely that they may be involved in generating the correct number of cortical neurones from the ventricular germinal zones, or in controlling mitotic division and/or the persistence of neurones once they have reached their proper position in the cerebral cortex. At present, 57 genes and 52 ESTs map to the $M C P H 2$ region on chromosome 19q13.1-13.2 (G3 map, Genemap98. http://www.ncbi.nlm.nih.gov/ genemap98/), the majority of which are expressed in the central nervous system. The neurally expressed gene $C T G 3 a$, a homologue of the mouse numb gene, maps to this region. ${ }^{16}$ Mouse numb appears to be involved in specifying cell fates during neurogenesis ${ }^{17}$ and therefore could be a strong candidate for $\mathrm{MCPH} 2$ primary microcephaly.

As yet no good animal models have emerged for primary microcephaly. This may be due to the large relative size of the human cerebral cortex so that microcephaly may be difficult to detect or may not occur in other species. Alternatively, the developmental expression patterns for genes that cause primary microcephaly may be different in humans compared to other species or the genes may be human-specific.

Analysis of further families will refine the minimum critical regions for the $M C P H 1$ and $M C P H 2$ loci, generate relative incidence figures for these separate primary microcephaly loci and may also give insights into genotype/phenotype correlations. Identifying the genes that cause human autosomal recessive primary microcephaly will have two major areas of impact; firstly, that families could be offered confirmatory diagnosis for their child with primary microcephaly and subsequent prenatal diagnosis; secondly, that genes 


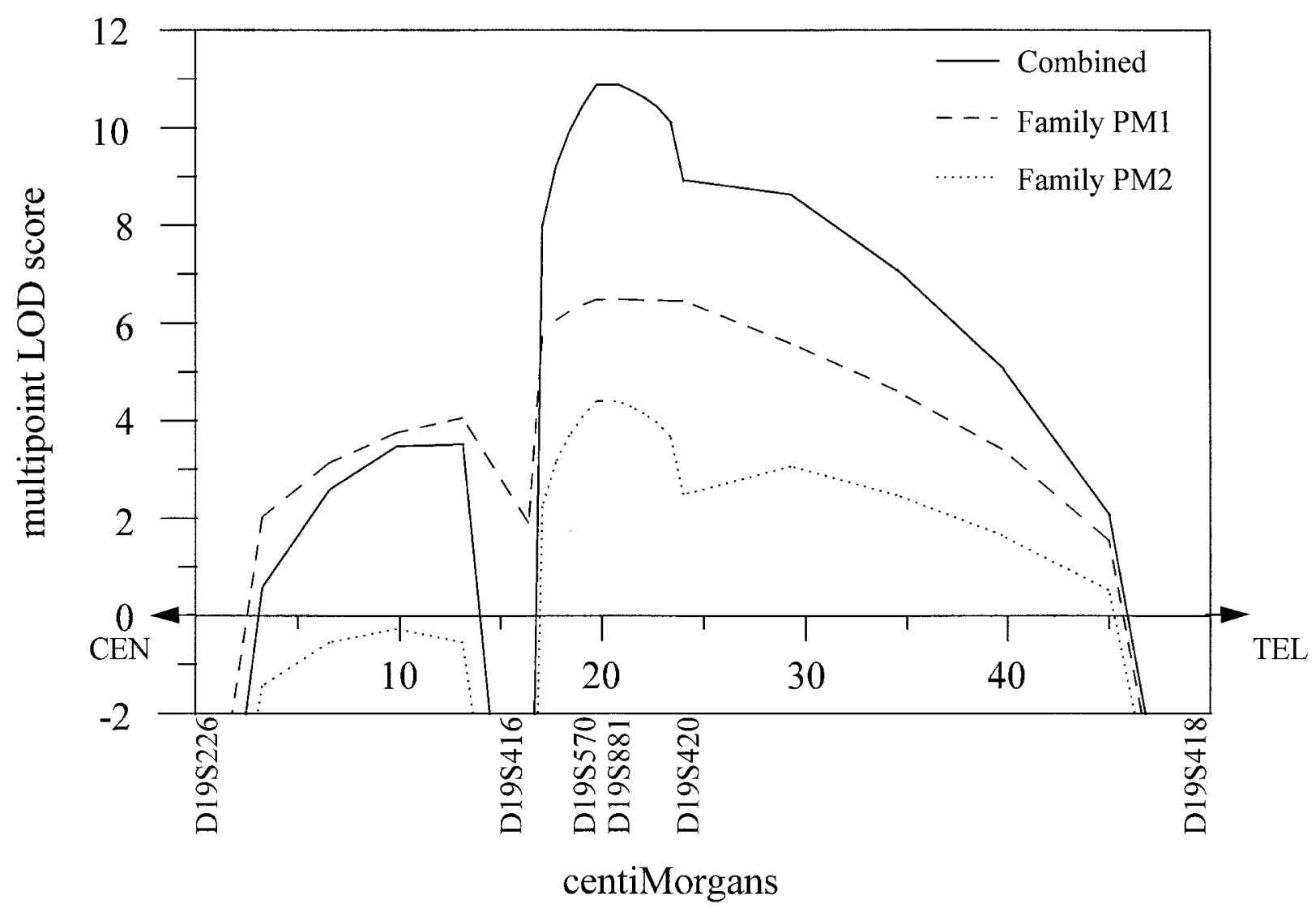

Figure 3 Results of GENEHUNTER multipoint analysis for markers on $19 q$ for families PM1 and PM2

may be identified that are involved in the complex developmental evolution of the human brain.

\section{Acknowledgements}

We thank the West Riding Medical Research Trust, the Medical Research Council, the Wellcome Trust and Action Research for providing funding support for this work. Research in the authors' laboratories is also supported by Northern and Yorkshire Regional Health Authority, Yorkshire Cancer Research and the Birth Defects Foundation. We thank the families for participation in this study and Dr TJ Keen for useful discussions.

\section{References}

1 Böök JA, Schut JW, Reed SC: A clinical and genetical study of microcephaly. Am J Menr Defic 1953; 57: 637-660.

2 Qazi QH, Reed TE: A problem in diagnosis of primary versus secondary microcephaly. Clin Genet 1973; 4: $46-52$.
3 Ross JJ, Frias JL: Microcephaly. In: Vinken PJ, Bruyn GW (eds). Congenital Malformations of the Brain and Skull: Handbook of Clinical Neurology. Elsevier Holland Biomedical Press: Amsterdam, 1977, vol30 (part 1), pp 507-524.

4 Bundey S: Microcephaly. In: Emery AEH (ed). Genetics and Neurology; Genetics in Medicine and Surgery. Churchill Livingstone: Edinburgh, 1992, pp 20-24.

5 Baraister M: Microcephaly. In: Motulsky AG, Bobrow M, Harper PS, Scriver C (eds). The Genetics of Neurological Disorders. Oxford monographs on medical genetics. Oxford Medical Publications: Oxford, 1990, vol18: pp 26-33.

6 Sujatha M, Kumari CK, Murty JS: Segregation frequency in microcephaly. Hum Genet 1989; 81: 388-390.

7 Cohen T, Zeitune M, McGillivray BC et al: Segregation analysis of microcephaly. Am J Med Genet 1996; 65: 226-234.

8 Komai T, Kishimoto K, Ozaki Y: Genetic study of microcephaly based on Japanese material. Am J Hum Genet 1955; 7: 51-65.

9 Van den Bosch J: Microcephaly in the Netherlands a clinical and genetical study. Ann Hum Genet 1959; 23: 91-116.

10 Cowie V: The genetics and sub-classification of microcephaly. J Ment Defic Res 1960; 4: 42-47. 
11 Jackson AP, McHale DP, Campbell DA et al: Primary autosomal recessive microcephaly $(\mathrm{MCPH1})$ maps to chromosome 8p22-pter. Am J Hum Genet 1998; 63: $542-546$.

12 Tolmie JL, McNay M, Stephenson JB, Doyle D, Connor JM: Microcephaly: genetic counselling and antenatal diagnosis after the birth of an affected child. Am J Med Genet 1987; 27: 583-594.

13 Terwilliger JD, Ott J: Handbook of human genetic linkage. The Johns Hopkins University Press: Baltimore, 1984.

14 Kruglyak L, Daly MJ, Reeve-Daly MP, Lander ES: Parametric and nonparametric linkage analysis: a unified multipoint approach. Am J Hum Genet 1996; 58: 1347-1363.
15 Williams RW, Strom RC, Goldwitz D: Natural variation in neuron numbers in mice is linked to a major quantitative trait locus on chromosome 11. J Neurosci 1998; 18: 138-146.

16 Margolis RL, Abraham MR, Gatchell SB et al: cDNAs with long CAG trinucleotide repeats from human brain. Hum Genet 1997; 100: 114-122.

17 Zhong W, Feder JN, Jiang M-N, Jan LY, Jan YN: Asymmetric localisation of a mammalian Numb homologue during mouse cortical neurogenesis. Neuron 1996; 17: 43-53. 